\title{
El trabajo de Ibn Firnás
}

The Work of Ibn Firnas

\author{
Rafael Diego Macho ReYes \\ Universidad de Córdoba \\ b02marer@uco.es
}

Resumen: La figura de Ibn-Firnás (810-886) es una de las representativas del área de filosofía, ciencia e investigación del Emirato Independiente de Córdoba, que es la fase inicial de la administración musulmana del territorio de la península ibérica entre el 756 y el 929, dando paso al Califato Omeya de Córdoba, del 929 al 1031 y los Reinos de Taifas entre el 1031 y el 1492, etapas en las que se organizaría la dominación musulmana de la Península.

Ibn-Firnás era miembro de una familia de origen bereber que vino en la primera fase de intervención de conquista liderada por Tarik y su familia se asentó en la sierra de la actual provincia de Málaga, trasladándose a Córdoba en su juventud para su formación y desarrollo personal, siendo un intelectual protegido por tres emires. Tal y como se reflejaría en los arquetipos intelectuales del Renacimiento (siglo Xv), unos siete siglos después, es por ello que conocer su figura puede suponer no solo una valorización del personaje en sí, si no también un argumento a favor de la diversidad y el desarrollo del conocimiento que al-Ándalus supuso en el marco de la Edad Media europea. 
Por otra parte, el desarrollo de conocimiento en áreas tan diferenciadas como la óptica, la aeronáutica, la poesía o la música, hacen de su figura un referente cultural a valorizar, divulgar y comunicar que permita ofrecer nuevas perspectivas y contexto histórico.

Palabras clave: Ibn-Firnás, pensamiento, al-Ándalus, ingeniería, herencia cultural.

Abstract: The figure of Ibn-Firnás (810-886) is one of the representatives of the area of philosophy, science and research of the Independent Emirate of Córdoba, which is the initial phase of the Muslim administration of the territory of the Iberian Peninsula between 756 and 929, giving way to the Umayyad Caliphate of Córdoba, from 929 to 1031 and the Taifa Kingdoms between 1031 and 1492, stages in which the Muslim domination of the Peninsula would be organized.

Ibn-Firnás was a member of a family of Berber origin that came in the first phase of the conquest intervention led by Tarik and his family settled in the mountains of the current province of Málaga, moving to Córdoba in their youth for their training and development personal, being an intellectual protected by three emirs. As would be reflected in the intellectual archetypes of the Renaissance ( $15^{\text {th }}$ century), 7 centuries later, that is why knowing his figure can suppose not only an appreciation of the character itself, but also an argument in favour of diversity and the development of knowledge that al-Andalus supposed in the framework of the European Middle Ages.

On the other hand, the development of knowledge in areas so differentiated as optics, aeronautics, poetry or music, make his figure a cultural reference to value, disseminate and communicate that allows offering new perspectives and historical context. 
Keywords: Ibn-Firnas, philosophy, al-Andalus, engineering, cultural heritage.

Fecha de recepción: 27/4/2021

Fecha de aceptación: 22/11/2021

Macho Reyes, Rafael Diego (2022). «El trabajo de Ibn Firnás». Monograma. Revista Iberoamericana de Cultura y Pensamiento, n. ${ }^{\circ}$ 10, pp. 143-161. doi: 10.36008/monograma.2022.10.0344. http: revistamonograma.com. ISSN: 2603-5839. 

Ibn Firnás: biografía y contexto bistórico

El arabista e historiador Mahmud Ali Makki (Makki, 1997, 39), describe a Abu l-Qasim Abbäs Ibn Firnâs como el primer Humanista, teniendo en cuenta el concepto de humanismo que se desarrollará durante el Renacimiento entre los siglos XV o XVI. Este concepto no sería tan rompedor si tenemos en cuenta que nombrar a Ibn Firnás como tal, supondría adelantar el concepto de humanismo cinco siglos, hasta la ciudad Ronda (Málaga) en el año 810, año en el que, bajo el Emirato de Al-Haken I, nace nuestro protagonista.

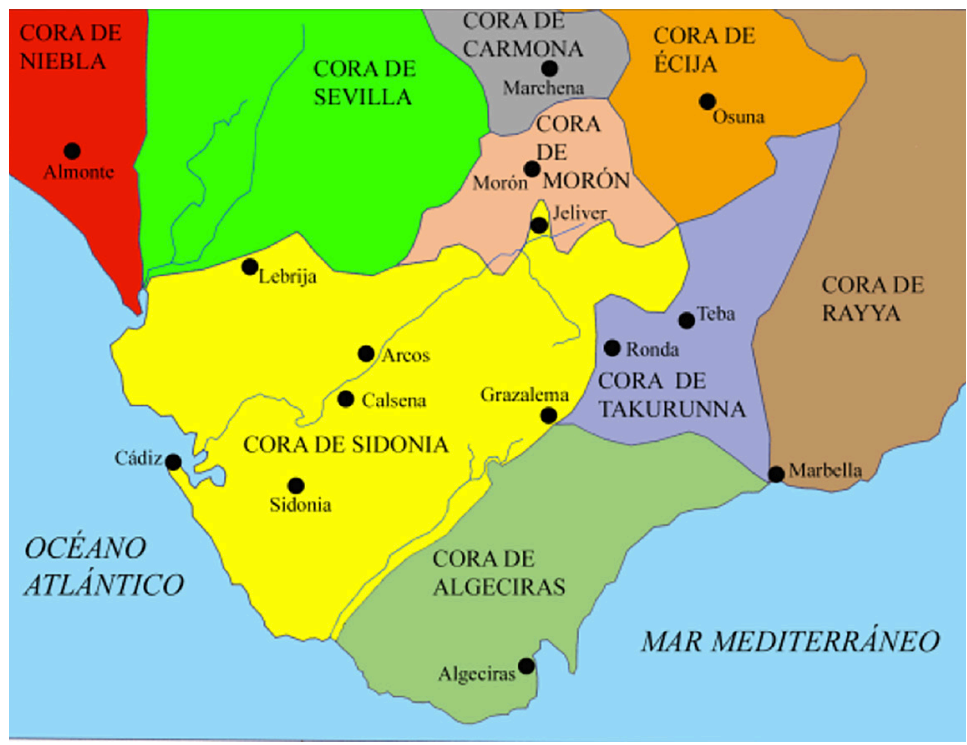

Figura 1. Ubicación de la cora de Sidonia.

Fuente: https://comarcadelajanda.wordpress.com/jornadas. 
La cora de Takurunna contaba con Ronda como la capital de dicha zona y fue un territorio destinado a acoger a las tropas bereberes que desembarcaron en al-Ándalus con la conquista y pese a que el asentamiento ya contaba con cerca de 100 años desde la toma, Ronda no ofrecía el mismo acceso al conocimiento y la prosperidad que sí otorgaba la capital del Emirato, Corduba.

La corte Al-Haken I dio paso en el año 822 al Emirato de Abderramán, Abderramán II quien tuvo que enfrentarse a varias conspiraciones durante su reinado comenzando por las constantes pretensiones al trono de su tío Abd-Alláh.

De este paso entre su nacimiento hasta la llegada a la corte no se conserva documentación que justifique su transformación y educación hasta llegar a formar parte de la corte del Emir, donde será cliente (en el sentido latino del término, vasallo) y protegido de los emires Abderramán II y de su hijo Mohamed I.

La corte de Abderramán II era un bullicioso espacio de intercambio cultural y político, entre sus diferentes acciones llevó a cabo la reorganización interna y administrativa de al-Ándalus, generó una ceca propia para la emisión de su propia moneda e hizo más eficiente la recaudación de impuestos, fundó Murcia (825) tras derrotar a los muradíes y lanzó populistas aceifas contra el Reino de Galicia y el Reino de Navarra (843). Finalmente, amplió la Mezquita Alhama de Córdoba en lo que hoy en día se llama «la segunda ampliación» (imagen). En el imaginario colectivo cordobés es el emir que ajustició a los alborotadores mozárabes conocidos como los Santos Mártires (852) por su postrer ataque al concepto de Profeta de Mahoma.

Será sucedido por su hijo Mohamed I, quien establecerá un emirato continuista al anterior, realizando un intento de mante- 
nimiento del emirato a través de campañas militares frente a sus rivales de la familia Banu Qasi a los que llegó a aplastar y derrotar en el año 860 en la aceifa de conquista sobre el Reino de Navarra. En el año 871, nuevas revueltas en Toledo fueron sofocadas y supusieron la fundación de varias plazas, entre ellas Madrid, para poder controlar al poder de los posibles rebeldes en la zona.

Seis años antes de su muerte, en el 880, una nueva serie de sublevaciones sumirán al Emirato en un caos militar y administrativo, que al menos en la Capital no supone un gran cambio en el ambiente cortesano donde Ibn Firnás desarrolló su labor.

Los emires, siempre consideraron a Firnás como un elemento de creación e inteligencia en la corte y a él se atribuyen un amplio desarrollo de elementos técnicos en la corte de Córdoba, así como mucho talento en el campo literario y musical, rivalizando con el popular Ziryab. En la siguiente sección se analizará el patrimonio intelectual desarrollado por este pensador andalusí teniendo en cuenta, que, sobre todo, la herencia cultural provista por este personaje se enmarca a través de documentos secundarios, narraciones ajenas y referencias de coetáneos o comentarios de varios autores, porque, a parte de algunas colecciones de versos ${ }^{1}$ no ha quedado testimonio directo de la producción científico-técnica de Ibn Firnás ni de forma física ni teórica. No hay un «códice» como en el caso de su principal heredero Leonardo da Vinci, sin embargo, sí se puede dar carta de veracidad a la importancia del pensador por todas las referencias sobre su trabajo, desde otros estudios académicos actuales ${ }^{2}$, otros traba-

1 Rubiera Mata, M. ${ }^{a}$ J. (2004). Literatura Hispanoárabe. Alicante: Publicaciones Universidad de Alicante pp. 62-63.

2 Acedo del Olmo Ordóñez, Antonio R. (2017). «El sabio Abbás Ibn Firnás, un "renacentista" del siglo ix». En Martínez Enamorado, V. y Siles Guerrero, F. (eds.), Anejos de Takurunna n. ${ }^{2}$. Actas del II Congreso Internacional de Historia de la Serranía de Ronda entre al-Ándalus y los Inicios de la Edad Moderna. Siglos VIII-ХИ, pp. 355-368. 
jos a través de la historia o bien, narraciones sobre la historia de al-Ándalus de la época como las de Ibn Hayyan ${ }^{3}$, o incluso glosas sobre sus propias invenciones. Es por este motivo y el contraste de fuentes que tomaremos esos testimonios como fidedignos y los enumeraremos en esta obra.

\section{Ibn Firnás: obra cientifico-técnica}

La mayor parte de la obra científico técnica de la que se tiene conocimiento de Firnás está recogida en sus propios escritos, o bien, se la conoce por vía secundaria a partir de otros autores coetáneos que la describen con términos muy locuaces y efectistas en los que destacan lo impresionante o útil de sus diseños, citando entre los cuales:

- Rediseño de la clepsidra: una clepsidra es un reloj de agua por fuga que marca el paso del tiempo teniendo en cuenta la salida controlada de agua por un orificio en una vasija, cuanto más vacía está la vasija, mayor velocidad de paso de tiempo ha ocurrido. Conocer y medir mejor el tiempo tenía múltiples aplicaciones tanto en la logística de la época como en el de navegación, por tanto, este avance pudo suponer una mejora destacada en el Emirato.

- Alta manipulación de cristal: hasta el desarrollo de los plásticos generalizados durante el siglo xx y hasta la metalurgia avanzada e industrial de la revolución técnica del siglo $\mathrm{XIX}$, pocos materiales eran tan versátiles y fácilmente trabajables como el cristal, pero su manipulación más precisa y variada fue una incorporación cultural que no se

3 Martínez Enamorado, V. (2008). «Ibn Hayyan, el abanderado de la historia de alÁndalus». Jábega, n. ${ }^{\circ}$ 97, pp. 30-34.

Macho Reyes, Rafael Diego (2022). «El trabajo de Ibn Firnás». Monograma. Revista Iberoamericana de Cultura y Pensamiento, n. ${ }^{\circ}$ 10, pp. 143-161. doi: 10.36008/monograma.2022.10.0344. http: revistamonograma.com. ISSN: 2603-5839. 
vería en Europa hasta el desarrollo del Gótico entre los siglos XII-XIII, sin embargo, en el mundo islámico y su relación por la ruta de la seda con los ingenieros y científicos asiáticos, permitieron desarrollar técnicas que Ibn Firnás consiguió imponer en Córdoba, realizando, de forma acreditada hasta construcciones y pabellones de cristal con funciones que incluían hasta la formación de planetarios ${ }^{4}$.

- Estudios aeronáuticos: el aspecto más conocido de Ibn Firnás es la leyenda que señala que se arrojó desde el Castillo de la Arruzafa, hoy desaparecido bajo el Parador Nacional y durante unos segundos planeó por el cielo hasta que se dio de bruces con el suelo, rompiéndose las piernas y quedando inválido durante el resto de su vida. Pero esto no es material de leyenda. Esto fue un hecho. En el año 852, Ibn Firnás desarrolló un sistema de paracaídas que le permitió reducir el peso de su caída y hacer que una caída mortal desde el Alminar de la Mezquita Aljama y reducir su impacto, el trabajo en el área de aeronáutica tuvo su cénit por parte del autor con el desarrollo de su ingenio de planeo siguiendo un patrón alas fijas de madera y seda, en el año 875,12 años antes de su muerte, acometió la hazaña que le dio su sitio en la historia.

El castillo de la Arruzafa se localizaba en la falda de la sierra de Córdoba y era un edificio de función habitacional y administrativa de los cadíes del Emirato. Actualmente está bajo el Parador Nacional y es el emplazamiento de origen para la prueba de vuelo que Ibn Firnás realizó.

4 Acedo del Olmo Ordóñez, Antonio R. (2015). Abbas Ibn Firnás. El sabio de Al Ándalus. Cádiz: La Serranía. 


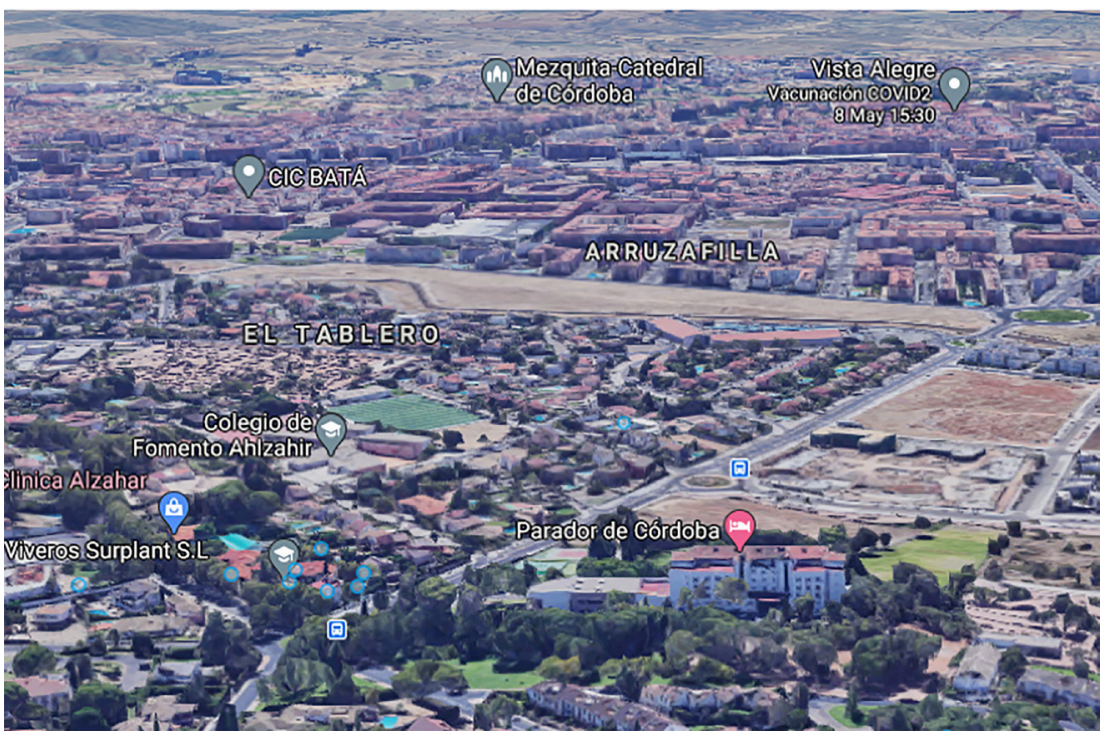

Figura 2. Imagen sobre el punto de salida de Ibn Firnás (Parador de Córdoba), orientado hacia el valle en dirección sur-sureste.

Fuente: Google Maps.

Desde otra perspectiva, el vuelo de Ibn Firnás se refiere como un vuelo corto en el tiempo de duración por lo que no podríamos suponer un enorme desplazamiento desde el punto de salida.

\section{Ibn Firnás: obra literaria-filosófica}

El trabajo intelectual de Ibn Firnás se centró en el aspecto científico y técnico sobre todo, sin embargo, estudios como el realizado por Von Schack ${ }^{5}$, señalan a la poesía como la actividad

5 Von SchaK, F. (1867). Poesía y arte de los árabes en España y Sicilia (traducción de Juan Valera). Madrid: M. Rivadeneyra, 3 vols. (Edición original: Poesie und Kunst der Araber in Spanien und Sicilien. Berlín: W. Herst, 1865), pp. 84-86.

Macho Reyes, Rafael Diego (2022). «El trabajo de Ibn Firnás». Monograma. Revista Iberoamericana de Cultura y Pensamiento, n. ${ }^{\circ}$ 10, pp. 143-161. doi: 10.36008/monograma.2022.10.0344. http: revistamonograma.com. ISSN: 2603-5839. 
más sublime de la cultura islámica en aquella época y dominar la métrica y la composición era una de las cumbres intelectuales de la época, de una forma muy parecida al dominio de las artes plásticas de los artistas renacentistas.

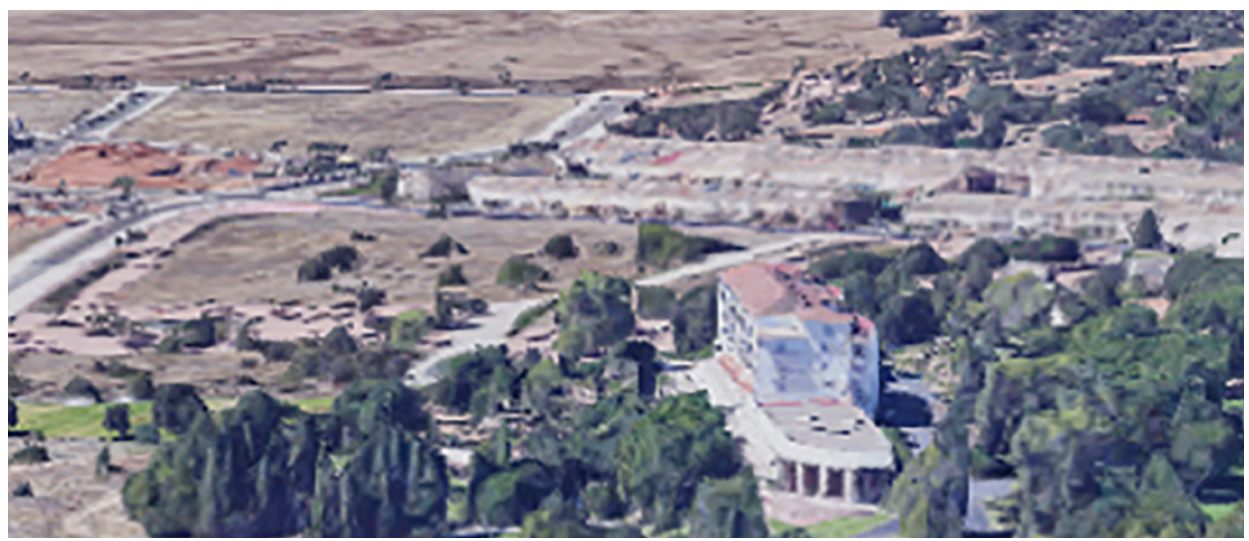

FIguRa 3. Imagen sobre el punto de salida de Ibn Firnás (Parador de Córdoba), orientado hacia el valle en dirección sur-sureste.

Fuente: Google Maps.

\section{Ibn Firnás: obra literaria-filosófica}

El trabajo intelectual de Ibn Firnás se centró en el aspecto científico y técnico sobre todo, sin embargo, estudios como el realizado por Von $\mathrm{Schack}^{6}$, señalan a la poesía como la actividad más sublime de la cultura islámica en aquella época y dominar la métrica y la composición era una de las cumbres intelectuales de la época, de una forma muy parecida al dominio de las artes plásticas de los artistas renacentistas.

6 Von SCHAK, F. (1867). Poesía y arte de los árabes en España y Sicilia (traducción de Juan Valera). Madrid: M. Rivadeneyra, 3 vols. (Edición original: Poesie und Kunst der Araber in Spanien und Sicilien. Berlín: W. Herst, 1865), pp. 84-86. 
La obra lírica de Ibn Firnás es uno de los primeros intentos de poesía estructurada y con una métrica estudiada de la que se tiene constancia en al-Ándalus, teniendo en cuenta, además que este autor es el primer autor andalusí en componer estrofas siguiendo estructuras científicas según la nueva métrica desarrollada en Bagdad por Jalil Ibn Ahmad en la sede del califato Abbasida.

La poesía de Ibn Firnás es una obra de carácter cortesano en su mayoría donde se reflejan loas al Emir y a sus victorias mili$\operatorname{tares}^{7}$ o bien, narran pasajes descriptivos de la naturaleza y de la actividad cinegética $^{8}$

Ha quedado Toledo despoblada, a merced de las aves de rapiña.

Ha quedado sin gente, desguarnecida, (silenciosa) como una tumba.

No ha querido Allah que subsista un puente erigido para el paso de las tropas infieles.

Me levanté a la amanecida, cuando la noche se apelotona de tinieblas y la aurora se esconde en los pliegues de su manto negro.

Fui con el de las orejas colgantes, adiestrado y ya conocedor;

el que parece tener su boca mellada, el que es esbelto cuando se estira, bello cuando se encoge, como la letra árabe lám;

nos sorprendió un conejo detrás de un arbusto y el perro saltó sobre él como sacre vigoroso: cuando iba uno detrás del otro,

no había entre ellos sino la distancia de un paso;

sus giros son tan rápidos que no lo imaginarías: es como si se curvase con la flexibilidad de un cálamo.

7 Terés, E. «Ábbás Ibn Firnás». Al-Ándalus, vol. 25, n. ${ }^{\circ}$ 1, 1960, p. 248.

8 Rubiera Mata, M. ${ }^{a}$ J. (2004). Literatura Hispanoárabe. Alicante: Publicaciones Universidad de Alicante, pp. 62-63. 
En otros aspectos, diversos estudios como el de «La enseñanza entre los musulmanes españoles» de Julián Ribera y Tarragó ${ }^{\text {, }}$ catedrático de Literatura Arábiga Española en la Universidad de Madrid (Actual Universidad Complutense de Madrid), destaca la labor también en el desarrollo de la música y el canto, a la altura del fabuloso músico y gastrónomo Ziryab, con quien rivalizaba en habilidad y gusto.

\section{Ibn Firnás en la actualidad}

Aunque para el conjunto de la ciudadanía se puede asociar a la figura romántica del sabio árabe, es un personaje relativamente poco conocido para la gran población. En la actualidad hay multitud de trabajos de asociaciones históricas, lúdicas, elementos arquitectónicos o descubrimientos científicos de diferentes niveles que pretenden rendir homenaje a su trabajo.

- Juego «Córdoba»: al bucear en la historia de nuestro protagonista se puede llegar a la conclusión de que no es un personaje desconocido para la Academia, sin embargo, no se puede decir lo mismo del gran público. En el año 2007, la Asociación Cultural «Jugamos Todos» de Córdoba, dedicada al mundo de los juegos de mesa y el ocio y tiempo libre de forma responsable, se embarcó en un proyecto de edición de un Juego con el popular autor Reiner Knizia y el ilustrador Raúl «Raulo» Cáceres (ver figura 4) sobre la ciudad de Córdoba. El juego consiste en emplear los valores de unas cartas para conquistar diferentes zonas de la Córdoba de al-Ándalus y ganar según los puntos conquistados, pero lo interesante del proyecto viene cuando

\footnotetext{
9 Ribera y TARragó, J. (1925). La Enseñanza entre los Musulmanes Españoles. Córdoba: Publicaciones de la Real Academia de Córdoba, p. 57.
} 
se analizan los elementos de juego y se comprueba que las cartas que permiten ganar la partida están dedicadas a diferentes personalidades del mundo cultural de Córdoba, entre los que figura Ibn-Firnás. Este proyecto no comercial, se desarrolló haciendo que el juego no pudiese comprarse, si no que, participando en actividades de la Asociación pudiese adquirirse. Junto con el juego, se incluía una pequeña reseña de los personajes mencionados para mayor valor histórico del proyecto. Puede que sea un homenaje compartido, pero también puede ser uno de los de mayor penetración sobre todo en edades jóvenes al asociar a través del juego la diversión y las ganas de aprender con un personaje de renombre de nuestra historia.

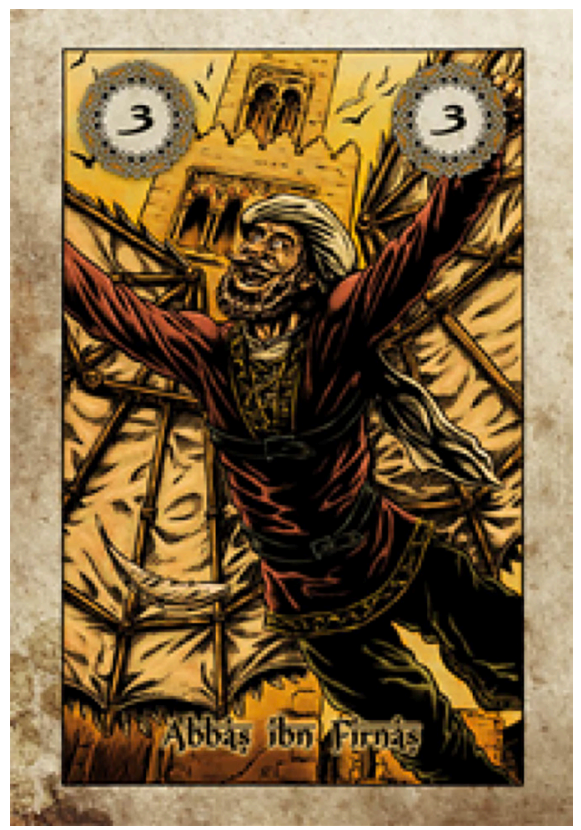

Figura 4. Detalle del juego «Córdoba».

Fuente: https://www.jugamostodos.org/RKCORDOBA/castellano/index. 
- Puente de Córdoba: hacia las afueras de Córdoba, en dirección hacia el sur-sureste, orillando en la dirección entre Málaga y Sevilla, Córdoba despide al visitante con el espectacular puente dedicado a nuestro protagonista.

El puente, una construcción mixta entre puente con pilares y colgante se abre como las alas de un ave de lado a lado del puente y rinde homenaje a uno de los primeros trabajos completos sobre aeronáutica y aerodinámica de la historia.

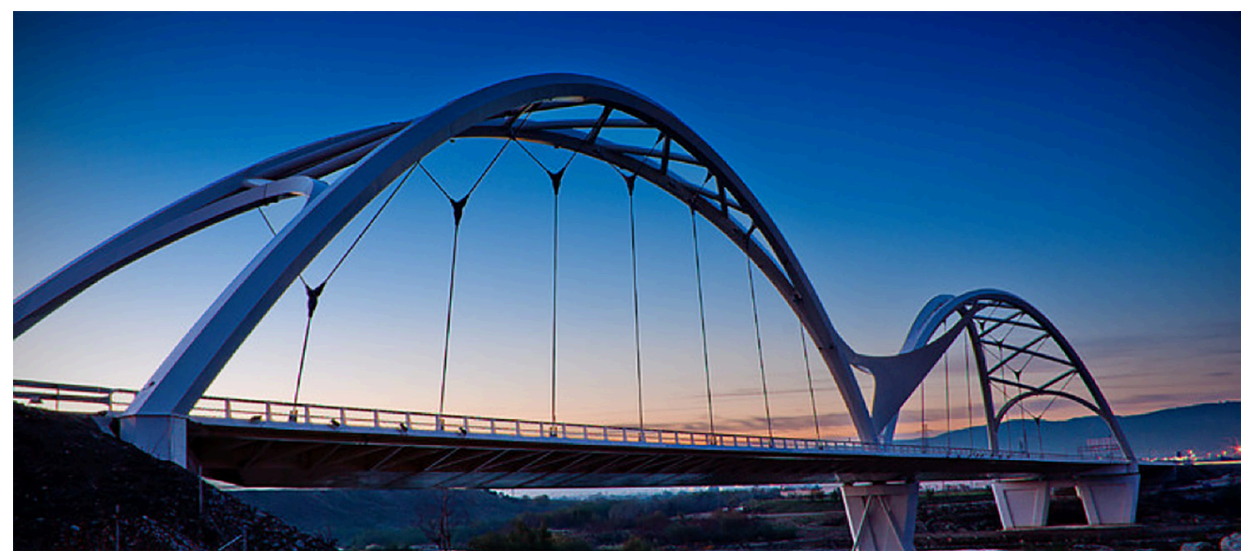

Figura 5. Puente dedicado a Ibn Firnás en Córdoba. Fuente: https://www.eltiempo.es/fotos/en-provincia-cordoba/ puente-de-abbas-ibn-firnas.html.

El puente, obra del ingeniero José Luis Manzanares Japón, se inauguró en 2011 tras cuatro años de construcción y hoy en día supone una estupenda ayuda a la hora de comunicar uno de los polígonos industriales de la Ciudad hacia el sur y otros destinos comerciales y el aeropuerto comercial de la misma ciudad. 
- Aeropuerto de Bagdad: preside dicho edificio una estatua del investigador que sobrevivió los bombardeos y las tensiones políticas de la invasión y guerra de Irak.

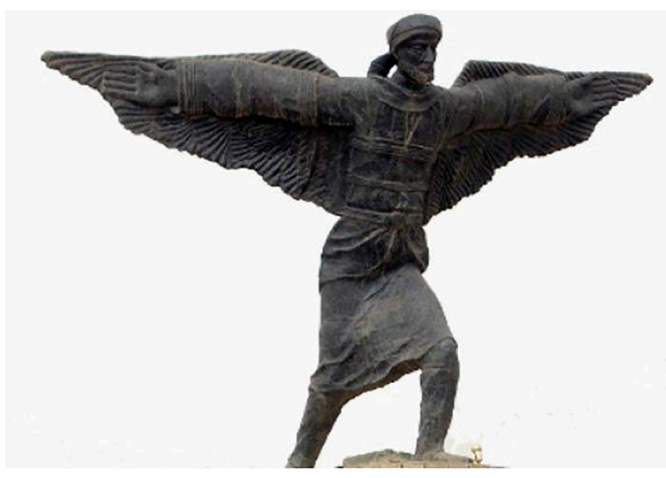

Figura 6. Estatua de Ibn Firnás en el aeropuerto de Bagdad.

Fuente: https://www.notascordobesas.com/2014/03/monumento-ab-

bas-ibn-firnas-el-leonardo.html.

- Cráter en la luna: en el año 1976, durante la caracterización de los cráteres de la Luna ${ }^{10}$, clasificó hasta tres cráteres como Ibn Firnás como homenaje a su figura.

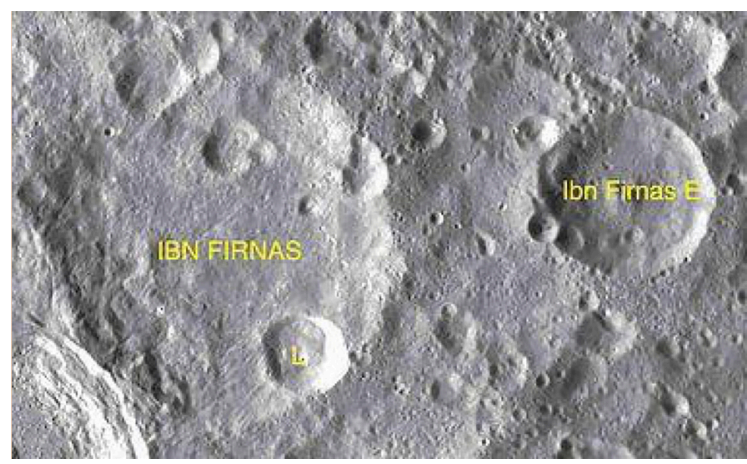

Figura 7. Cráteres de la Luna llamados en homenaje a Ibn Firnás. Fuente: АнАрей Щербаков, Wikimedia.

10 NASA-RP-1097, Andersson and Whitaker 1982, hereafter AW82.

Macho Reyes, Rafael Diego (2022). «El trabajo de Ibn Firnás». Monograma. Revista Iberoamericana de Cultura y Pensamiento, n. ${ }^{\circ}$ 10, pp. 143-161. doi: 10.36008/monograma.2022.10.0344. http: revistamonograma.com. ISSN: 2603-5839. 


\section{Valoración de su legado}

Córdoba ha sido descrita muchas veces como la ciudad «callada» o la ciudad discreta, sin embargo, cuando se zambulle en su historia, se llega a la conclusión de que no lo está, simplemente resuena el eco de su etapa de metrópoli en una actualidad de carácter más discreto y provincial.

La historia de al-Ándalus no se ha transmitido nunca adecuadamente al gran público, ni siquiera a la propia población andaluza. Años de educación histórica centralista y con un sesgo religioso católico han arrebatado la perspectiva a la ciudadanía de otra forma estatal que se desarrolló en la península ibérica durante casi ocho siglos adoptando diferentes formas y estructuras pero con un denominador común, el carácter religioso musulmán de sus élites en un territorio de herencia latina y visigoda. Dicho de otra forma, más integral y completa, tan Reyes de España son Abderramán III y Al Haken II como Witiza, Alfonso X El Sabio o Alfonso XII de Borbón.

El siglo XXI está siendo el siglo de la revisión, movimientos como «Me'Too» o «BlackLivesMatter» junto con la eclosión de las redes sociales, están permitiendo una aceleración de los cambios sociales inusitada en el siglo inmediatamente anterior. El estudio de la historia y la consideración cultural no pueden permanecer ajenos en este hecho, $y$ al igual que el método hipotético-deductivo de la ciencia permite corregir teorías, nuevas obras y descubrimientos desde la honestidad investigadora y la seriedad argumental deben de corregir, en este caso, omisiones de nuestro continuo histórico que doten a la sociedad de una panorámica más amplia de su historia, para conocer como su contexto actual ha sido modificado y en base a ese conocimiento histórico, y su propio razonamiento, poder tomar mejores 
decisiones, desarrollar mejores comportamientos y rechazar mensajes malintencionadamente equivocados.

Ibn Firnás fue un investigador multidisciplinar que, bajo el mecenazgo de la élite política de la capital de al-Ándalus, pudo desarrollar invenciones y obra poética para mayor gusto y gloria del Emir y que, supondría los antecesores de elementos ornamentales y avances técnicos que tardarían en verse en el mundo occidental del que nuestra cultura es heredera casi 600 años, en el Renacimiento. Entender que este personaje tiene la misma entidad cultural española como la pueden tener Turriano, Torres Quevedo o Margarita Salas, nos puede servir en el actual contexto de tensiones diplomáticas y migratorias frente a las estrategias ultranacionalistas y de corte neofascista a comprender que la humanidad siempre se adapta a las circunstancias nacionales y que al final, la capacidad intelectual y la progresía de la humanidad es un elemento transversal a todos nosotros.

La relación entre Ibn Firnás y los emires no parece prima facie muy diferente a la de Leonardo Da Vinci con Ludovico Sforza o con el Rey Francisco I, pero sí es interesante que muchos avances, incluido el propio planeador de Leonardo o similares fuesen diseñados con cerca de cuatro siglos de anterioridad. La injusticia de la xenofobia histórica y la islamofobia europea supuso no seguir con el estudio de este personaje en mayor profundidad para conocer que la Edad Media no fue un elemento de estudio estable y constante y que el conocimiento que luego sería retomado, fue, en gran parte, concentrado, transmitido e investigado en lo que fue un Emirato, posteriormente un califato y acabarían siendo unas taifas fue cultivado por parte de una serie de intelectuales que durante siete siglos formaron parte de la historia de España y por supuesto, de Europa. 


\section{REFERENCIAS BIBLIOGRÁFICAS}

Acedo del Olmo Ordóñez, Antonio R. (2015). Abbas Ibn Firnás. El sabio de Al Ándalus. Cádiz: La Serranía.

— (2017). «El sabio Abbás Ibn Firnás, un "renacentista” del siglo IX». En Martínez Enamorado, V. y Siles Guerrero, F. (eds.), Anejos de Takurunna n. ${ }^{\circ}$ 2. Actas del II Congreso Internacional de Historia de la Serranía de Ronda entre al-Ándalus y los Inicios de la Edad Moderna. Siglos VIII-XVI, pp. 355-368.

Martínez Enamorado, V. (2008). «Ibn Hayyan, el abanderado de la historia de al-Ándalus». Jábega, n. ${ }^{\circ}$ 97, pp. 30-34.

Ribera y TARragó, J. (1925). La Enseñanza entre los Musulmanes Españoles. Córdoba: Publicaciones de la Real Academia de Córdoba, p. 57.

Rubiera Mata, M. J. (2004). Literatura Hispanoárabe. Alicante: Publicaciones Universidad de Alicante.

Terés, E. «Abbás Ibn Firnás». Al-Ándalus, vol. 25, n. '1, 1960, p. 248.

Von Schak, F. (1867). Poesía y arte de los árabes en España y Sicilia (traducción de Juan Valera). Madrid: M. Rivadeneyra, 3 vols. (Edición original: Poesie und Kunst der Araber in Spanien und Sicilien. Berlín: W. Herst, 1865), pp. 84-86. 